\section{The effect of experimentally altered cognitive appraisal on pain tolerance}

\author{
RICHARD W. J. NEUFELD \\ University of Calgary, Calgary, Canada
}

Tolerance of radiant heat to the forearm was measured under three forms of cognitive appraisal: (1) thinking of the pain as being pleasurable (denial); (2) thinking of the pain as being a protective reaction of sensory nerves (intellectualization); (3) thinking of a blank wall (neutral). Ss were informed that each form of appraisal was endorsed by a different source: (1) an obstetrician, (2) a nurse's aide, and (3) a grade-nine student. Results indicated denial was significantly superior in raising pain tolerance to both the neutral appraisal as well as intellectualization. Also, the effects of the different cognitive appraisals varied in relation to the sources of endorsement, denial being ineffective when endorsed by the nurse's aide and intellectualization decreasing tolerance when endorsed by the grade-nine student. Discussion of results centered around the difference of the effects of cognitive appraisal on pain tolerance as compared to the effects on tolerance of experimental threat.

The importance of the effects of cognitive factors on tolerance of pain has been pointed out by several authors, e.g., Beecher (1957), Blitz \& Dinnerstein (1968), Conn (1961), Kanfer \& Goldfoot (1968), Nisbett \& Schachter (1966), and Zimbardo, Cohen, Wisenberg, Dworkin, \& Firestone (1966). These authors have emphasized the importance of anxiety and apprehension in Ss' cognitive appraisal of the pain experience as agents of decreased tolerance of the experience. Cognitive appraisal has been found to affect not only reaction to physical stress (pain) but reaction to psychological stress as well. Results reported by Speisman, Lazarus, Mordkoff, \& Davison (1964) and Lazarus \& Alfert (1964) showed that reaction to a stress-inducing motion-picture film could be modified by varying the commentary accompanying the film. Commentaries involving " "denial', of or "intellectualization" about the traumatic aspects of the film produced a reduction in stress reaction. The research presented here investigated the effects on pain tolerance of procedures similar to those used by the above investigators to decrease reaction to the stress film. Question has been raised as to what extent the effects of certain procedures on psychological-stress reaction are paralleled when the procedures are used in relation to physical stress (e.g., Bobey \& Davidson, in press).

Inasmuch as clinicians often report differential effects of stress-reducing procedures depending on the characteristics of the individual recommending the "treatment," the respective stress-reducing procedures under investigation were presented to the $S s$ as though endorsed by different clinical personnel.

\section{METHOD}

The Ss were 12 ( 7 females and 5 males) experimentally naive undergraduates from the University of Calgary.

The radiant-heat apparatus was used to produce the experimental pain as this method has been shown to be both convenient and reliable (Hall, 1953: Davidson \& McDougall, 1969). The apparatus was based on the Hardy-Wolff-Goodell model modified by Clark \& Bindra (1956). A wooden box containing a $250-\mathrm{W}$ infrared lamp delivered constant $110 \mathrm{mc} / \mathrm{cm}^{2}$ heat through a round hole $2 \mathrm{~cm}$ in diam to the $S$ 's forearm. A Stoelting timer, attached to the apparatus through a relay, recorded the duration of the heat.

Three sets of instructions designed to have Ss manipulate their cognitive appraisal of the pain experience and three different "endorsers" of the instructions were included in the study. A randomized-block partially-confounded factorial design (Kirk, 1968) was adopted as this design allowed three pain-tolerance measures per $S$, one for each set of cognitive-appraisal instructions. In addition, a different source could purportedly endorse the following of each respective set of instructions as an effective method for coping with pain.

Each $S$ was assigned randomly to one of the six blocks of instructionendorser combinations. After entering the experimental room, $\mathrm{S}$ was told that in doing research into methods of increasing people's ability to cope with pain, E had consulted several sources, and the current experiment sought to test the recommendations of the respective sources.

After the above briefing, the S's inner forearms were darkened with india ink to ensure absorption of the heat. A sufficiently large portion of each forearm was darkened to prevent overlap of the areas where the heat would be administered during the three successive measures. The $S$ then read a printed passage appropriate to the first instruction-endorser combination assigned to him, and his pain tolerance was measured on each forearm. Tolerance was taken as the time in seconds between the onset of the heat and when $S$ pressed a switch terminating the heat. Tolerance score was taken as the average of the measures on both forearms. Measures were similarly taken after each of the second and third assigned written passages had been read. The order of presentation of the assigned passages was randomized for each S. After the last measure had been taken, a short debriefing was presented.

Two sets of instructions aimed at affecting cognitive appraisal on the part of $S$ were adopted from procedures labeled by Speisman e t al (1964) as "intellectualization" and "denial." The printed passages with the intellectualization instructions informed $S$ that one source contacted by $E$ (see a description of the fictitious sources below) recommended, as a help in coping with pain, thinking of pain as being "just a reaction of sensory nerves which is a protective mechanism." The passage requested $S$ to test this suggestion by thinking about the pain as the source had recommended during the application of the radiant heat.

The printed passage ${ }^{1}$ with the denial instructions informed the $S$ that a second source endorsed "thinking of the sensation as being pleasurable and thinking of the experience as being enjoyable." The $S$ was again asked to follow the suggestion of the source while the radiant heat was applied.

A third cognitive-appraisal instruction was labeled "neutral." Here, the written passage requested the $S$ to use a method of coping with pain suggested by a third source. The method was "to think of nothing in particular-to think of a blank wall" while the heat was applied.

The sources supposedly consulted by $\mathrm{E}$ were an "eminent Canadian obstetrician," a "nurse's aide from a local hospital," and a "student from a local grade-nine class." These sources were selected as representing a clinician of relatively high status, a clinician of lesser status, and a nonclinician, respectively.

\section{RESULTS}

Analysis of variance indicated a significant main effect for the different cognitive-appraisal instructions $(\mathrm{F}=7.5$, $\mathrm{df}=2.16, \mathrm{p}<.01)$. Tukey's w procedure (Kirk. 1968) for multiple comparisons 
indicated the mean pain tolerance for denial of 71.5 was significantly higher than the mean for the neutral instructions of $54.2(\mathrm{q}=3.58, \mathrm{df}=16, \mathrm{p}<.06)$ as well as the mean for intellectualization of 45.4 $(q=5.41, \quad d f=16, \quad p<.01) . \quad$ Variance among the "main-effect" means corresponding to the obstetrician, nurse's-aide, and grade-nine student endorsers $(\bar{X}=60.4, \quad \bar{X}=54.6$, and $\bar{X}=56.2$, respectively) was statistically insignificant $(F<1)$ unlike the Instructions by Endorsers interaction $(\mathrm{F}=3.40, \mathrm{df}=4,16, \mathrm{p}<.05)$. Analysis of the interaction indicated that the denial instructions ( $\bar{X}=88.3$ ) led to significantly higher pain tolerance than the neutral instructions $(\bar{X}=38.0)$ when instructions were endorsed by the obstetrician $(\mathrm{q}=5.9$, $\mathrm{df}=16, \quad \mathrm{p}<.01)$. Also, there was a significant difference between the denial mean $(\bar{X}=79.8)$ and the intellectualization mean $(\bar{X}=25.1)$ when instructions were endorsed by the grade-nine student $(q=6.5, \mathrm{df}=16, \mathrm{p}<.01)$. There were no significant differences among the three instruction means when endorsement was by the nurse's aide ( $\bar{X}$ for denial $=45.6, \bar{X}$ for intellectualization $=56.1$, and $\bar{X}$ for the neutral instructions $=61.2$ ).

\section{DISCUSSION}

The "main-effect" superiority in increasing pain tolerance of the cognitive-appraisal instructions involving "denial of the pain" tends to confirm the contention that procedures leading to increased tolerance of physical stress may be different from those increasing tolerance of psychological stress (Bobey \& Davidson, in press). Speisman et al (1964) found that for a sample of university students a stress-film commentary emphasizing intellectualization was more effective than a denial commentary in reducing stress reaction to the film. However, the opposite was true of the student sample included in the present study using the administration of physical stress.

The common clinical suggestion that stress-reducing treatments have different effects for different clinical personnel was confirmed. For those designated as clinicians, it was found that endorsement of instructions by an obstetrician rendered the denial instructions effective in raising pain tolerance, while no instructions were effective when endorsed by the nurse's aide. The difference between the means for the obstetrician endorsement $(\overline{\mathrm{X}}=88.3)$ and the nurse's aid endorsement $(\bar{X}=46.5)$ when the denial instructions were presented was statistically significant $(q=4.9, d f=16, p<.01)$. The reason why pain tolerance was significantly lower for the intellectualization instructions than for the denial instructions when endorsement was by the nonclinician is not clear, especially since the difference between pain tolerance under the neutral instructions $(\bar{X}=63.7)$ as compared to that under the denial instructions $(\bar{X}=79.8)$ was not significant $(q=1.9, \quad d f=16$, $p>.10)$. It is possible that the instructions involving content of an intellectual nature were incompatible with endorsement by a grade-nine student leading to apprehension about their efficacy, with resulting increased anxiety over the pain experience and subsequent decreased pain tolerance (Conn, 1961).

The procedures designed to manipulate cognitive appraisal used in this study differed from those of Speisman et al (1964) and Lazarus \& Alfert (1964) as the Ss were asked to manipulate their own cognitive appraisal rather than $E$ manipulating cognitive appraisal by programming the $S$ 's experience in the laboratory. However, it might be argued that the present study more closely resembles the real-life situation in that cognitive defenses against stress are instigated by the stressed individual himself.

It is possible that a fruitful study for future research would be an investigation of the generalizability to clinical pain of the present results relating to experimental pain (Beecher, 1957).

\section{REFERENCES}

BEECHER, H. K. The measurement of pain. Pharmacological Review, 1957, 9, 59-209. BLITZ, B., \& DINNERSTEIN, A. Effects of different types of instructions on pain parameters. Journal of Abnormal Psychology, $1968,73,276-280$.

BOBEY, M., \& DAVIDSON, P. O. Psychological factors that affect pain tolerance. Joumal of Psychosomatic Research, in press.

CLARK, J. W., \& BINDRA, D. Individual differences in pain thresholds. Canadian Journal of Psychology, 1956, 10, 69-76.

CONN, J. $H$. The inter-relationship between anxiety and pain. Journal of the American Society of Psychosomatic Dentistry \& Medicine, 1961, 8, 40-52.

DAVIDSON, P. O., \& McDOUGALI, C. E. The generality of pain tolerance. Journal of Psychosomatic Research, 1969, 13, 83-89.

HALL, K. R. L. Studies of cutaneous pain: A survey of research since 1940 . British Journal of Psychology, 1953, 44, 279-294.

KANFER, F., \& GOLDFOOT, P. Self-control and tolerance of noxious stimulation. Psychological Reports, 1966, 18, 79-85.

KIRK, R. E. Experimental design: Procedures for the behavioral sciences. New York: McGraw-Hill, 1968.

LAZARUS, R. S., \& ALFERT, E. Short-circuiting of threat by experimentally altering cognitive appraisal. Journal of Abnormal \& Social Psychology, 1964, 69, 195-205.

NISBETT, R. E., \& SCHACHTER, S. The cognitive manipulation of pain. Journal of Experimental Social Psychology, 1966, 2, 227-236.

SPEISMAN, J. C., LAZARUS, R. S., MORDKOFF, A. M., \& DAVISON, L. A. Experimental reduction of stress based on ego-defense theory. Joumal of Abnormal \& Social Psychology, 1964, 68, 367-380.

ZIMBARDO, P., COHEN, A. R., WEISENBERG, M., DWORKIN, L., \& FIRESTONE, I. Control of pain motivation by cognitive dissonance. Science, 1966, 151, 217-219.

\section{NOTE}

1. The complete printed passages may be obtained by writing the author.

\title{
The effect of a coding cue on verbal discrimination learning*
}

\author{
SHARRON S. WIKE and EDWARD L. WIKE \\ The University of Kansas, Lawrence, Kans. 6604
}

This study investigated the effect of the oral presentation of an English word as a coding cue for the correct CVC in a verbal discrimination task. The Ss were 22 undergraduates, 11 to a group. It was found that the group given the English words similar to the corresponding nonsense syllables made significantly fewer errors on the test trial.

It has been found that giving $S$ a coding cue along with a trigram facilitates short-term memory of that trigram (Lindley, 1963; Schaub \& Lindley, 1964; Lindley \& Nedler, 1965). Thus, giving S the word "view" helped $S$ to remember

* These studies were supported by a grant, HD 00870 , from the National Institute of Child Health and Human Development and a Biomedical Sciences Support grant, FR-07037.
VUJ. Presumably the trigram was encoded by means of the cue and at the time recall decoding (i.e., from "view" to VUJ) took place.

In verbal discrimination learning, $S$ does not have to learn the response in the same way that he does in a paired-associate, serial, or short-term memory task-the correct syllable is given to him along with the incorrect syllable. It is not a matter of 